\title{
Production of D-Allose From D-Allulose Using Commercial Immobilized Glucose Isomerase
}

\section{OPEN ACCESS}

Edited by:

Lucia Gardossi,

University of Trieste, Italy

Reviewed by:

Wenli Zhang,

Jiangnan University, China

Harumi Veny,

Universiti Teknologi MARA, Malaysia

*Correspondence:

Yeong-Su Kim

yskim@kiam.or.kr

tThese authors have contributed equally to this work and share first

authorship

Specialty section:

This article was submitted to

Industrial Biotechnology,

a section of the journal

Frontiers in Bioengineering and

Biotechnology

Received: 16 March 2021

Accepted: 24 June 2021

Published: 15 July 2021

Citation:

Choi MN, Shin K-C, Kim DW,

Kim B-J, Park C-S, Yeom S-J and

Kim Y-S (2021) Production of D-Allose

From D-Allulose Using Commercial

Immobilized Glucose Isomerase.

Front. Bioeng. Biotechnol. 9:681253.

doi: 10.3389/fbioe.2021.681253

\section{Mi Na Choi ${ }^{1+}$, Kyung-Chul Shin ${ }^{2 \dagger}$, Dae Wook Kim, Baek-Joong Kim³ , Chang-Su Park ${ }^{4}$, Soo-Jin Yeom ${ }^{5}$ and Yeong-Su Kim ${ }^{1 *}$}

${ }^{1}$ Wild Plants Industrialization Research Division, Baekdudaegan National Arboretum, Bonghwa, South Korea, ${ }^{2}$ Department of Integrative Bioscience and Biotechnology, Konkuk University, Seoul, South Korea, ${ }^{3}$ Starch and Sweetener Research Department, Ingredient R\&D Center, DAESANG Corporation, Icheon, South Korea, ${ }^{4}$ Department of Food Science and Technology, Daegu Catholic University, Gyeongsan, South Korea, ${ }^{5}$ School of Biological Sciences and Technology, Chonnam National University, Gwangju, South Korea

Rare sugars are regarded as functional biological materials due to their potential applications as low-calorie sweeteners, antioxidants, nucleoside analogs, and immunosuppressants. D-Allose is a rare sugar that has attracted substantial attention in recent years, owing to its pharmaceutical activities, but it is still not widely available. To address this limitation, we continuously produced D-allose from D-allulose using a packed bed reactor with commercial glucose isomerase (Sweetzyme IT). The optimal conditions for D-allose production were determined to be $\mathrm{pH} 8.0$ and $60^{\circ} \mathrm{C}$, with $500 \mathrm{~g} / \mathrm{L}$ D-allulose as a substrate at a dilution rate of $0.24 / \mathrm{h}$. Using these optimum conditions, the commercial glucose isomerase produced an average of $150 \mathrm{~g} / \mathrm{L}$ D-allose over 20 days, with a productivity of $36 \mathrm{~g} / \mathrm{L} / \mathrm{h}$ and a conversion yield of $30 \%$. This is the first report of the successful continuous production of $\mathrm{D}$-allose from $\mathrm{D}$-allulose by commercial glucose isomerase using a packed bed reactor, which can potentially provide a continuous production system for industrial applications of D-allose.

Keywords: D-allose, D-allulose, rare sugar, packed bed reactor, Sweetzyme IT, glucose isomerase

\section{INTRODUCTION}

A first-generation sweetener is a sweetness-oriented sugar such as sucrose, fructose, and glucose. Second-generation sweeteners are low-calorie and high-sweetness sugars, including the sugar alcohol xylitol, sucralose, aspartame, and oligosaccharides, which participate in intestinal regulation. Currently, functional rare sugars are drawing attention as third-generation sweeteners.

A rare sugar is defined as a monosaccharide that is rarely found in nature according to the International Society of Rare Sugars (ISRS) (Izumori, 2002, 2006). There are more than 50 kinds of rare monosaccharides. Two of these, D-tagatose and D-allulose, but not D-allose, have been formally approved by the United States Food and Drug Administration (FDA) as Generally Recognized As Safe (GRAS), and are allowed for use in the food industries (Levin, 2002; Kim, 2004; Mu et al., 2012). 
The rare sugar D-allose has attracted substantial attention in recent years because of its beneficial biological properties as an anti-cancer (Sui et al., 2005a,b; Mitani et al., 2009; Kanaji et al., 2018), anti-oxidant (Murata et al., 2003), anti-inflammatory (Gao et al., 2001), and anti-hypertensive (Kimura et al., 2005) agent, and its ability to protect against ischemia-reperfusion injury of the liver (Hossain et al., 2003). Additionally, D-allose is a noncaloric and non-toxic sweetener that has approximately $80 \%$ the sweetness of sucrose (Chattopadhyay et al., 2014; Mooradian et al., 2017; Chen et al., 2018). Despite these various benefits, Dallose occupies a small proportion of the industrial market due to its scarcity and high production costs. Thus, the continuous production of D-allose is important for broadening its industrial applications. However, only the production of $\mathrm{D}$-allose using free enzyme has been studied until now. For the industrial production of D-allose, which is an important next-generation sweetener, it is necessary to study the application of a reactor using a food grade commercial enzyme.

D-Allose can be synthesized by chemical methods (Bernaerts et al., 1963; Baker et al., 1972) but some disadvantages exist from these approaches, such as complicated purification steps, undesirable by-products, environmental pollution from chemical waste, low productivity, and the inability to reuse substrates (Lim and Oh, 2011). For these reasons, the biological synthesis of D-allose is becoming a key foundation. Biologically, Dallose can be synthesized from D-glucose by a three-step enzyme-catalyzed pathway. In the first reaction, D-glucose is converted to $\mathrm{D}$-fructose by $\mathrm{D}$-glucose isomerase. The second reaction, the conversion of $\mathrm{D}$-fructose to $\mathrm{D}$-allulose, can be catalyzed by $\mathrm{D}$-tagatose 3-epimerase or D-allulose 3-epimerase. $\mathrm{D}$-Allose is produced in the final step by the conversion of $\mathrm{D}$ allulose by L-rhamnose isomerase from Clostridium stercorarium (Seo et al., 2018), Thermobacillus composti (Xu et al., 2017), Bacillus subtilis (Bai et al., 2015), or Pseudomonas sp. (Bhuiyan et al., 1998); by ribose-5-phosphate isomerase from Clostridium thermocellum (Park et al., 2007b) or Thermotoga lettingae (Feng et al., 2013); or by galactose 6-phosphate isomerase from Lactococcus lactis (Park et al., 2007a). Recently, a one-pot reaction method was reported to successfully produce D-allose from Dfructose using D-allulose 3-epimerase from Flavonifractor plautii and D-ribose-5-phosphate isomerase from C. thermocellum (Lee et al., 2018).

Here, we describe the first demonstration of the continuous production of D-allose from D-allulose using commercial foodgrade D-glucose isomerase (Sweetzyme IT; GI) in a packed bed reactor.

\section{MATERIALS AND METHODS}

\section{Materials}

Food-grade immobilized GI from Streptomyces murinus (Sweetzyme IT) was purchased from Novozyme (Kalubdborg, Denmark). D-allose, D-allulose, and other reagents were purchased from Sigma Aldrich (St. Louis, MO, United States). The packed bed reactor XK26/100 was purchased from GE Healthcare Life Science (Uppsala, Sweden).

\section{Enzyme Assay}

The activity of GI was measured in a reaction mixture containing $50 \mathrm{mM}$ EPPS buffer ( $\mathrm{pH} 8.0$ ), $10 \mathrm{~g} / \mathrm{L}$ D-allulose, and $10 \mathrm{mg} / \mathrm{mL}$ GI at $60^{\circ} \mathrm{C}$ for $30 \mathrm{~min}$. One unit of enzyme activity was defined as the amount of enzyme required to produce $1 \mu \mathrm{mol}$ of $\mathrm{D}$-allose from $\mathrm{D}$-allulose per minute at $60^{\circ} \mathrm{C}$ and $\mathrm{pH}$ 8.0.

\section{Optimization of D-Allose Production Conditions}

To determine the optimum $\mathrm{pH}$ and temperature for the GIcatalyzed production of allose, the reactions were performed for $30 \mathrm{~min}$ by varying the buffer $\mathrm{pH}$ from $\mathrm{pH} 4-9$ at $60^{\circ} \mathrm{C}$ and by varying the temperature from $40-90^{\circ} \mathrm{C}$ at $\mathrm{pH} 8.0$ using $10 \mathrm{~g} / \mathrm{L}$ D-allulose as a substrate. The thermostability of GI was monitored as a function of time for incubation by incubating the enzyme solution at different temperatures $\left(50-90^{\circ} \mathrm{C}\right)$ in $50 \mathrm{mM}$ EPPS buffer $(\mathrm{pH} 8.0)$. Samples were withdrawn at various time intervals and then assayed in $50 \mathrm{mM}$ EPPS buffer ( $\mathrm{pH} \mathrm{8.0)} \mathrm{containing} 10 \mathrm{~g} / \mathrm{L} \mathrm{D}$-allulose at $70^{\circ} \mathrm{C}$ for $30 \mathrm{~min}$.

\section{Continuous D-Allose Production}

The dilution rate and substrate concentration for continuous Dallose production in the packed bed reactor were investigated. The immobilized GI was packed into a XK26/100 packed bed reactor with a bed volume of $300 \mathrm{~mL}$ and the $\mathrm{D}$ allulose concentration was varied from 100 to $700 \mathrm{~g} / \mathrm{L}$ with a dilution rate of $0.24 / \mathrm{h}$ for $5 \mathrm{~h}$. The optimum dilution rate was determined by varying the rate from 0.07 to $0.95 / \mathrm{h}$ using a $500 \mathrm{~g} / \mathrm{L}$ D-allulose solution and a Gilson Mini Plus evolution peristaltic pump (Gilson, Inc., WI, United States) at $60^{\circ} \mathrm{C}$. The conversion yield was calculated as the percentage of the concentration of the produced D-allose as a product in relation to the concentration of $\mathrm{D}$-allulose as a substrate put in the reaction.

\section{Analytical Methods}

D-Allulose and D-allose concentrations were determined using a Bio-LC system (Dionex ICS-3000, Sunnyvale, CA, United States) with an electrochemical detector and a CarboPac PAI column. The column was eluted at $30^{\circ} \mathrm{C}$ with $0.1 \mathrm{M} \mathrm{NaOH}(0-5 \mathrm{~min})$, followed by a linear gradient of sodium acetate $(0-0.2 \mathrm{M})$ at $1 \mathrm{~mL} / \mathrm{min}$ for 5-35 $\mathrm{min}$.

\section{Nuclear Magnetic Resonance Analysis}

The nuclear magnetic resonance (NMR) spectra of D-allose were recorded on a Bruker $800 \mathrm{MHz}$ spectrometer (Bruker, Karlsruhe, Germany) using standard Bruker pulse programs. Chemical shifts were given as $\delta$-values with reference to tetramethylsilane (TMS) as an internal standard. ${ }^{1} \mathrm{H}$ and ${ }^{13} \mathrm{C}$ NMR assignments were determined by gHSQC, gHMBC, and ${ }^{1} \mathrm{H}-{ }^{1} \mathrm{H}-\mathrm{COSY}$. 


\section{RESULTS AND DISCUSSION}

\section{D-Allose Production From D-Allulose Using a Commercial Enzyme}

Previously, D-allose has been produced using microbial enzymes, including L-rhamnose isomerase (Seo et al., 2018), D-ribose-5phosphate isomerase (Feng et al., 2013), D-galactose-6-phosphate isomerase (Park et al., 2007a), and D-glucose-6-phosphate isomerase (Yoon et al., 2009). The most effective enzyme reported to date was L-rhamnose isomerase (Lim and Oh, 2011; Mu et al., 2012; Chen et al., 2018). The conserved protein domain family of L-rhamnose isomerase belongs to the AP2Ec super-family; this family includes other sugar-converting enzymes such as xylose (D-glucose) isomerase. The substrate specificities of commercial glucose isomerase from S. murinus (Sweetzyme IT, GI) and Lrhamnose isomerase from Dictyoglomus turgidum have also been reported for L-rhamnose and D-fructose (Kim et al., 2013, 2018).

Not only does GI catalyze the reversible isomerization of Dglucose and D-xylose to D-fructose and D-xylulose, respectively, but the isomerization of allose was catalyzed by a recombinant GI from Streptomyces sp. (Brucher et al., 2018) and a partially purified D-xylose isomerase from Streptomyces albus (Sanchez and Smiley, 1975). In this study, GI converted D-allulose to D-allose, and the specific activity of GI for D-allulose was 2.4- and 2.0-fold lower than those for D-glucose and D-xylose, respectively. Nevertheless, activity of GI toward D-allose was approximately 624-fold higher than that of a partially purified Dxylose isomerase from $S$. albus (Table 1). Thus, we successfully produced D-allose using D-allulose as a substrate by immobilized GI (see the reaction scheme in Figure 1). The reaction product was identified as a D-allose by NMR spectroscopy (Supplementary Figures 1-5). Commercial GI was used in this case because this enzyme provides enhanced reaction stability and better process control with minimization of the pressure drop issue by a large particle size of $0.4-1.0 \mathrm{~mm}$, and it can be applied to the industrial production of D-allose (Allen et al., 1979). Using our system, the conversion yield of D-allulose to D-allose catalyzed by GI was approximately 30\%. Previously reported conversion yields of $\mathrm{D}$-allose from $\mathrm{D}$-allulose using microbial enzymes such as L-rhamnose isomerases from C. stercorarium (Seo et al., 2018), T. composti KWC4 (Xu et al., 2017), B. subtilis WB600 (Bai et al., 2015), Caldicellulosiruptor saccharolyticus (Lin et al., 2011), Thermoanaerobacterium saccharolytium NTOU1 (Lin et al., 2010), Bacillus pallidus Y25 (Poonperm et al., 2007), and Pseudomonas stutzeri (Morimoto et al., 2006) were 33, 23, $37.5,33,34,35$, and 25\%, respectively. The yields using Dribose 5-phosphate isomerases from C. thermocellum (Park et al., 2007b) and T. lettingae TMO (Feng et al., 2013) were 33\% and $32 \%$, respectively, and those using D-galactose-6-phosphate isomerase from L. lactis (Park et al., 2007a) and D-glucose-6phosphate isomerase from Pyrococcus furiosus (Yoon et al., 2009) were 28,25 , and $32 \%$, respectively. This difference in conversion yields is expected to be due to reaction environmental factors such as temperature, and $\mathrm{pH}$, and type of reactor, because the equilibrium between $\mathrm{D}$-allulose and $\mathrm{D}$-allose is constant. To date, there are no studies using a reactor to produce $\mathrm{D}$-allose from
TABLE 1 | Specific activity of Gl for sugars.

\begin{tabular}{lcc}
\hline Substrate & Product & Specific activity $(\boldsymbol{\mu} \mathbf{m o l} / \mathbf{m i n} / \mathbf{m g})$ \\
\hline D-Glucose & D-Fructose & $367 \pm 32$ \\
D-Xylose & D-Xylulose & $316 \pm 15$ \\
D-Allulose & D-Allose & $156 \pm 33$ \\
D-Ribose & D-Ribulose & $87 \pm 7$ \\
L-Rhamnose & L-Rhamnulose & $103 \pm 11$ \\
D-Galactose & D-Tagatose & $N D$ \\
\hline
\end{tabular}

ND, not detected.

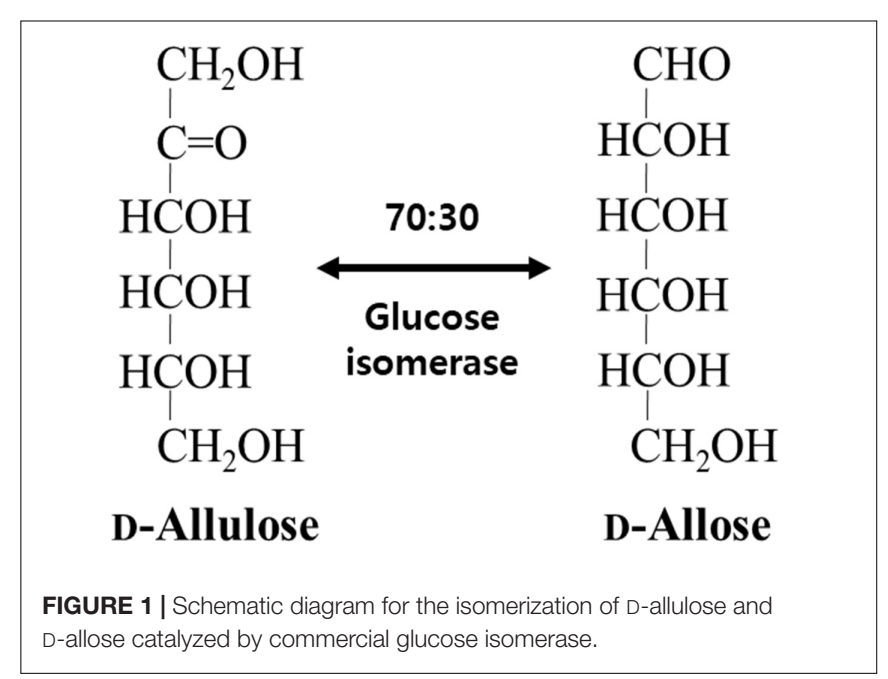

D-allulose. Although GI showed a lower conversion yield than many enzymes, it was applied to a packed bed reactor in this study because it is easy to industrialize as a commercially available immobilized enzyme.

\section{Effect of $\mathrm{pH}$ and Temperature on D-Allose Production}

The optimum $\mathrm{pH}$ and temperature for $\mathrm{D}$-allose production using GI were investigated using a $\mathrm{pH}$ range of 4-9 and a temperature range of $40-90^{\circ} \mathrm{C}$. Maximum GI activity was observed at $\mathrm{pH} 8.0$ and $90^{\circ} \mathrm{C}$ (Supplementary Figure 6). However, the thermostability of GI at $90^{\circ} \mathrm{C}$ could not sustain the production of D-allose (Figure 2). The half-life of GI activity at 50, 60, 70, 80 , and $90^{\circ} \mathrm{C}$ was $1,021,854,352,47$, and $17 \mathrm{~h}$, respectively. As a result, the optimum $\mathrm{pH}$ and temperature for the GI-catalyzed production of $\mathrm{D}$-allose were determined to be $\mathrm{pH} 8.0$ and $60^{\circ} \mathrm{C}$, respectively. For the GI-catalyzed production of D-fructose from $\mathrm{D}$-glucose and of L-rhamnulose from L-rhamnose, the optimum conditions were reported to be a $\mathrm{pH} 8.0-8.5$ and $60-70^{\circ} \mathrm{C}(\mathrm{Kim}$ et al., 2018). The optimal conditions for the production of $\mathrm{D}$ allose using L-rhamnose isomerases from C. stercorarium (Seo et al., 2018), T. composti KWC4 (Xu et al., 2017), B. subtilis WB600 (Bai et al., 2015), immobilized L-rhamnose isomerase from P. stutzeri (Morimoto et al., 2006), D-ribose-5-phosphate isomerase from C. thermocellum (Park et al., 2007b), D-galactose6-phosphate isomerase from L. lactis (Park et al., 2007a), and 


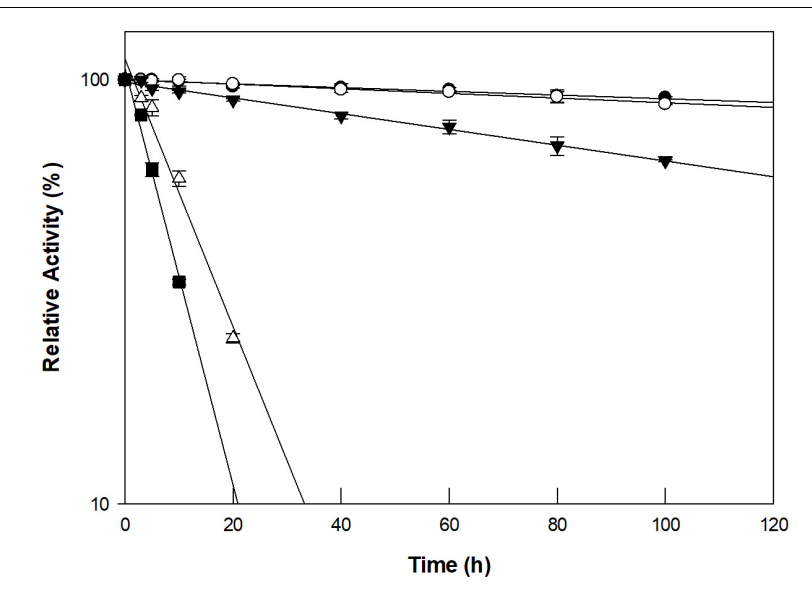

FIGURE 2 | Thermal inactivation of Gl catalyzing D-allose production at $50^{\circ} \mathrm{C}$ (closed circles), $60^{\circ} \mathrm{C}$ (open circles), $70^{\circ} \mathrm{C}$ (closed inverted triangles), $80^{\circ} \mathrm{C}$ (open triangles), and $90^{\circ} \mathrm{C}$ (closed squares). The enzyme was incubated at temperatures ranging from 50 to $90^{\circ} \mathrm{C}$ for varying periods of time. A sample was withdrawn at each time interval and assayed for enzyme activity in $50 \mathrm{mM}$ EPPS buffer (pH 8.0) containing $10 \mathrm{~g} / \mathrm{L}$ D-allulose at $60^{\circ} \mathrm{C}$ for $30 \mathrm{~min}$. The experimental data for thermal deactivation of the enzyme were fitted to a first-order curve and the half-life of the enzyme was calculated using Sigma plot 10.0 software (Systat software, San Jose, CA, United States). Data represent the means of three experiments \pm standard deviation (SD).

D-glucose-6-phosphate isomerase from P. furiosus (Yoon et al., 2009) were $\mathrm{pH} 7.0-9.0$ and $30-75^{\circ} \mathrm{C}$.

\section{Optimization of Reaction Conditions for Continuous D-Allose Production}

The concentration of $\mathrm{D}$-allulose as a substrate and its dilution rate for the production of $\mathrm{D}$-allose using $\mathrm{GI}$ were investigated in a packed bed reactor (XK26/100; i.d. $26 \mathrm{~mm} \times$ length $1,000 \mathrm{~mm}$ ). The enzyme was applied to the packed bed reactor with a working volume of $300 \mathrm{~mL}$. D-Allulose (100-700 g/L) was fed continuously into the packed bed reactor at $60^{\circ} \mathrm{C}$ with a dilution rate of $0.24 / \mathrm{h}$. The optimum concentration of D-allulose was $500 \mathrm{~g} / \mathrm{L}$ (Figure 3). The concentration of Dallose produced increased up to $600 \mathrm{~g} / \mathrm{L}$ D-allulose; however, the conversion yield of $\mathrm{D}$-allulose to $\mathrm{D}$-allose decreased when the D-allulose concentration exceeded $500 \mathrm{~g} / \mathrm{L}$. This may have been due to substrate inhibition at high concentrations. The optimum concentration of $\mathrm{D}$-allulose for $\mathrm{D}$-allose production using immobilized L-rhamnose isomerase from $P$. stutzeri was reported to be $500 \mathrm{~g} / \mathrm{L}$ (Morimoto et al., 2006) and that of Lrhamnose for L-rhamnulose production using GI was reported to be $300 \mathrm{~g} / \mathrm{L}$ (Kim et al., 2018).

The optimum dilution rate for the continuous production of D-allose using a packed bed reactor was investigated at different dilution rates ranging from 0.07 to $0.95 / \mathrm{h}$ (Figure 4). From 0.07 to $0.35 / \mathrm{h}$, the rate of production of $\mathrm{D}$-allose increased, but the productivity and conversion yield began to decrease after $0.24 / \mathrm{h}$, which is because the reaction time between the enzyme and the substrate shortens as the dilution rate increases. Thus, the optimal dilution rate for $\mathrm{D}$-allose production was estimated to be $0.24 / \mathrm{h}$.

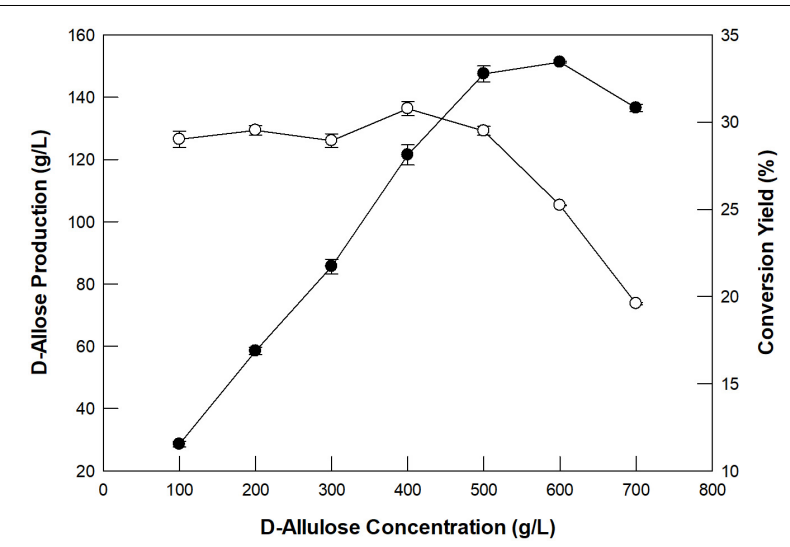

FIGURE 3 | Effect of substrate concentration on D-allose production (closed circles) and conversion yield (open circles) in a packed bed reactor. The reactions were performed in $50 \mathrm{mM}$ EPPS buffer $(\mathrm{pH}$ 8.0) containing $100-700 \mathrm{~g} / \mathrm{L} \mathrm{D}$-allulose at $60^{\circ} \mathrm{C}$ at a dilution rate of $0.24 / \mathrm{h}$. Data represent the means of three experiments $\pm \mathrm{SD}$.

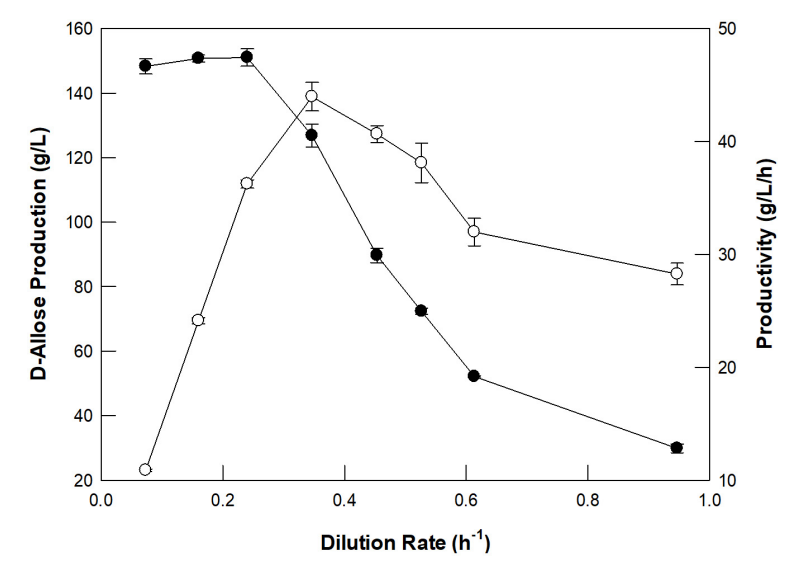

FIGURE 4 | Effect of the dilution rate of D-allulose on D-allose production (closed circles) and productivity (open circles) using a packed bed reactor. The working volume of the reactor was $300 \mathrm{~mL}$. A solution of $50 \mathrm{mM}$ EPPS buffer (pH 8.0) containing $500 \mathrm{~g} / \mathrm{L}$ D-allulose in the feeding reservoir was fed continuously into the reactor, and the effluent was allowed to flow out of the reactor to a reservoir using a peristaltic pump. The temperature was maintained at $70^{\circ} \mathrm{C}$ using a water circulator. Data represent the means of three experiments $\pm \mathrm{SD}$.

The optimum dilution rate for L-rhamnulose production from Lrhamnose using GI was reported to be 0.6/h (Kim et al., 2018). Although GI showed higher specific activity for D-allose than Lrhamnose, it was optimal at a lower dilution rate for D-allose than L-rhanmnose. This is presumably because the concentration of D-allose $(500 \mathrm{~g} / \mathrm{L})$ used in the reaction was higher than that of L-rhamnose (300 g/L).

\section{Continuous D-Allose Production in a Packed Bed Reactor}

GI was reused for 30 cycles with $500 \mathrm{~g} / \mathrm{L}$ D-allulose under batch reaction for $4 \mathrm{~h}$ (Supplementary Figure 7 ). In the first batch 


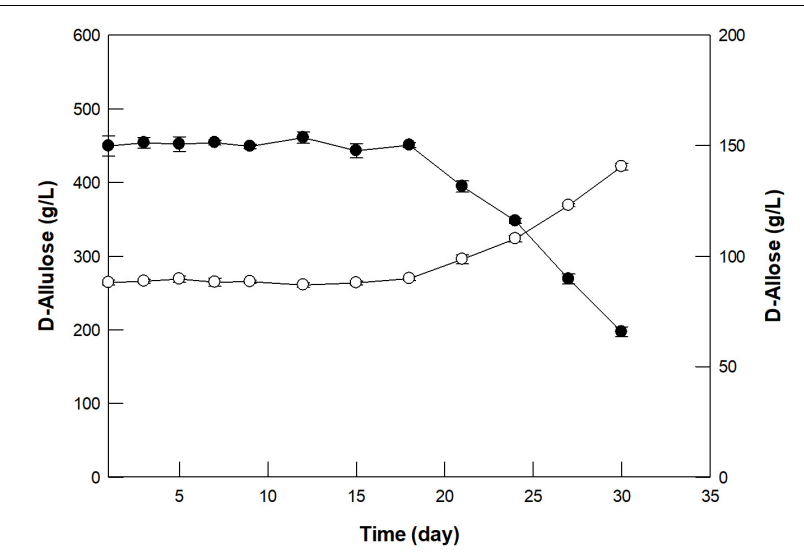

FIGURE 5 | Continuous production of D-allose (closed circles) from D-allulose (open circles) using immobilized $\mathrm{Gl}$ in a packed bed reactor. A solution of 50 mM EPPS buffer (pH 8.0) containing $500 \mathrm{~g} / \mathrm{L}$ D-allulose was fed continuously into the reactor, and the effluent was allowed to flow out of the reactor at a dilution rate of $0.24 / \mathrm{h}$. The reaction was performed at $60^{\circ} \mathrm{C}$ for 30 days. Data represent the means of three experiments \pm SD.

reaction, GI produced $150 \mathrm{~g} / \mathrm{L}$ D-allulose with a productivity of $37.5 \mathrm{~g} / \mathrm{L} / \mathrm{h}$, which was about 1. 4-, 17. 9-, and 7,500-fold higher than those by free enzymes such as D-ribose-5-phosphate isomerase from C. thermocellum (Park et al., 2007b), D-galactose6-phosphate isomerase from L. lactis (Park et al., 2007a), and glucose-6-phosphate isomerase from P. furiosus (Yoon et al., 2009), respectively. However, the productivity by GI was 2.1fold lower than that of 79.6 by L-rhamnose isomerase from C. stercorarium (Seo et al., 2018). Nevertheless, GI exhibited more than 95 and $65 \%$ residual activity for 20 and 30 cycles, respectively, indicating the possibility of continued use of GI in continuous D-allose production. Based on the above experiments, the optimal conditions for $\mathrm{D}$-allose production from $\mathrm{D}$-allulose using GI in a $300-\mathrm{mL}$ packed bed reactor were determined to be $\mathrm{pH} 8.0,60^{\circ} \mathrm{C}, 500 \mathrm{~g} / \mathrm{L} \mathrm{D}$-allulose, and a dilution rate of $0.24 / \mathrm{h}$. Using these conditions, $\mathrm{D}$-allose was produced continuously in the packed bed reactor for 30 days, a period within half-life, taking into account the thermostability at $60^{\circ} \mathrm{C}$ (Figure 5). An average of $150 \mathrm{~g} / \mathrm{L}$ D-allose was produced from $500 \mathrm{~g} / \mathrm{L}$ D-allulose substrate within 20 days, with a total of $5.18 \mathrm{~kg} \mathrm{D}$ allose, a productivity of $36 \mathrm{~g} / \mathrm{L} / \mathrm{h}$, and a conversion yield of $30 \%$. The D-allose concentration was reduced to approximately $43.9 \%$ after 30 days. In a previous report, immobilized L-rhamnose isomerase from $P$. stutzeri continuously produced $5.02 \mathrm{~kg}$ of Dallose from $16.6 \mathrm{~kg}$ of $\mathrm{D}$-allulose over 30 days, with a conversion yield of 30\% (Morimoto et al., 2006), which indicates about 1.5fold lower productivity than that by GI. Therefore, continuous production of D-allose by GI can be a good alternative for industrial applications.

\section{CONCLUSION}

Rare sugars are attracting attention as new functional materials because of their various biological properties. The rare sugars
D-tagatose and D-allulose have already been industrialized, but $\mathrm{D}$-allose has not. The rare sugar $\mathrm{D}$-allose has approximately $80 \%$ of the sweetness of common sugar, but without the calories, and it exhibits several beneficial biological properties. For industrialization research and application purposes, the mass production of D-allose must be supported. However, there are no continuous production systems in place for the commercial synthesis of D-allose. In this study, we demonstrated that commercial food-grade D-glucose isomerase (Sweetzyme IT) converts D-allulose to D-allose by NMR analysis, investigated substrate specificity of the enzyme. For the continuous production of $\mathrm{D}$-allose from $\mathrm{D}$-allulose in a packed bed reactor, optimum reaction conditions such as $\mathrm{pH}$, temperature, substrate concentration, and dilution rate were determined to be $\mathrm{pH} 8.0,60^{\circ} \mathrm{C}, 500 \mathrm{~g} / \mathrm{L} \mathrm{D}$-allulose, and $0.24 / \mathrm{h}$, respectively. Under the optimum condition, $150 \mathrm{~g} / \mathrm{L}$ of $\mathrm{D}$-allose was produced from $500 \mathrm{~g} / \mathrm{L}$ D-allulose, with a productivity of $36 \mathrm{~g} / \mathrm{L} / \mathrm{h}$ and a conversion yield of $30 \%$ within 20 days. This is a new approach for D-allose production, and to the best of our knowledge, this is the first report describing the continuous production of $\mathrm{D}$-allose using a commercial enzyme. These results can be helpful for the industrial production of $\mathrm{D}$-allose.

\section{DATA AVAILABILITY STATEMENT}

The original contributions presented in the study are included in the article/Supplementary Material, further inquiries can be directed to the corresponding author/s.

\section{AUTHOR CONTRIBUTIONS}

MC, K-CS, and Y-SK developed the concept and designed the manuscript. MC, K-CS, and DK provided key information and helped revise the manuscript. DK, B-JK, C-SP, and S-JY provided important intellectual support about experiment data. MC, K-CS, DK, B-JK, C-SP, S-JY, and Y-SK drafted the manuscript. All authors participated in writing and giving feedback on the manuscript and read and approved the final manuscript.

\section{FUNDING}

This work was supported by the National Research Foundation of Korea (NRF) grant funded by the Korean Government (MSIT) (grant numbers 2019R1F1A1059906 and 2018R1D1A1B07050820). This work was also supported by the KU Research Professor Program of Konkuk University. The funder had no role in the study design, in the collection, analysis, and interpretation of data, in the writing of the report, and in the decision to submit the article for publication.

\section{SUPPLEMENTARY MATERIAL}

The Supplementary Material for this article can be found online at: https://www.frontiersin.org/articles/10.3389/fbioe.2021. 681253/full\#supplementary-material 


\section{REFERENCES}

Allen, B. R., Charles, M., and Coughlin, R. W. (1979). Fluidized-bed immobilizedenzyme reactor for the hydrolysis of cornstarch to glucose. Biotechnol. Bioeng. 21, 689-706. doi: 10.1002/bit.260210413

Bai, W., Shen, J., Zhu, Y., Men, Y., Sun, Y., and Ma, Y. (2015). Characteristics and kinetic properties of L-rhamnose isomerase from Bacillus subtilis by isothermal titration calorimetry for the production of D-allose. Food Sci. Technol. Res. 21, 13-22. doi: 10.3136/fstr.21.13

Baker, D. C., Horton, D., and Tindall, C. G. Jr. (1972). Large-scale preparation of D-Allose: observations on the stereoselectivity of the reduction of 1,2:5,6-diO-isopropylidene- $\alpha$-D-ribo-hexofuranos-3-ulose hydrate. Carbohydr. Res. 24, 192-197. doi: 10.1016/S0008-6215(00)82279-X

Bernaerts, M. J., Furnelle, J., and De Ley, J. (1963). The preparation of some new disaccharides and D-allose from 3-ketoglycosides. Biochim. Biophys. Acta 69, 322-330. doi: 10.1016/0006-3002(63)91265-4

Bhuiyan, S. H., Itami, Y., Rokui, Y., Katayama, T., and Izumori, K. (1998). Dallose production from D-psicose using immobilized L-Rhamnose isomerase. J. Ferment. Bioeng. 85, 539-541. doi: 10.1016/S0922-338X(98)80104-9

Brucher, B., Vogel, A., Dudek, H. M., and Czaja, R. (2018). Glucose Isomerase. PCT Patent No WO2018202880. Rijswijk: European Patent Trademark Office.

Chattopadhyay, S., Raychaudhuri, U., and Chakraborty, R. (2014). Artificial sweeteners - a review. J. Food Sci. Technol. 51, 611-621. doi: 10.1007/s13197011-0571-1

Chen, Z., Chen, J., Zhang, W., Guang, C., and Mu, W. (2018). Recent research on the physiological functions, applications, and biotechnological production of D-Allose. Appl. Microbiol. Biotechnol. 102, 4269-4278. doi: 10.1007/s00253018-8916-6

Feng, Z., Mu, W., and Jiang, B. (2013). Characterization of ribose-5-phosphate isomerase converting D-psicose to D-allose from Thermotoga lettingae TMO Biotechnol. Lett. 35, 719-724. doi: 10.1007/s10529-013-1136-3

Gao, D., Kawai, N., and Tamiya, T. (2001). The anti-inflammatory effects of Dallose contribute to attenuation of cerebral ischemia-reperfusion injury. Med. Hypotheses 76, 911-913. doi: 10.1016/j.mehy.2011.03.007

Hossain, M. A., Izuishi, K., and Maeta, H. (2003). Protective effects of D-allose against ischemia reperfusion injury of the rat liver. J. Hepatobiliary Pancreat. Surg. 10, 218-225. doi: 10.1007/s00534-002-0785-8

Izumori, K. (2002). Bioproduction strategies for rare hexose sugars. Naturwissenschaften 89, 120-124. doi: 10.1007/s00114-002-0297-z

Izumori, K. (2006). Izumoring: a strategy for bioproduction of all hexoses. J. Biotechnol. 124, 717-722. doi: 10.1016/j.jbiotec.2006.04.016

Kanaji, N., Kamitori, K., Hossain, A., Noguchi, C., Katagi, A., Kadowaki, N., et al. (2018). Additive antitumour effect of dallose in combination with cisplatin in non-small cell lung cancer cells. Oncol. Rep. 39, 1292-1298. doi: 10.3892/or. 2018.6192

Kim, P. (2004). Current studies on biological tagatose production using L-arabinose isomerase: a review and future perspective. Appl. Microbiol. Biotechnol. 65, 243-249. doi: 10.1007/s00253-004-1665-8

Kim, Y. S., Kim, D. Y., and Park, C. S. (2018). Production of L-rhamnulose, a rare sugar, from L-rhamnose using commercial immobilized glucose isomerase. Biocatal. Biotransformation 36, 417-421. doi: 10.1080/10242422.2017.1388374

Kim, Y. S., Shin, K. C., Lim, Y. R., and Oh, D. K. (2013). Characterization of a recombinant L-rhamnose isomerase from Dictyoglomus turgidum and its application for L-rhamnulose production. Biotechnol. Lett. 35, 259-264. doi: 10.1007/s10529-012-1069-2

Kimura, S., Zhang, G. X., Nishiyama, A., Nagai, Y., Nakagawa, T., and Miyanaka, H. (2005). D-Allose, an all-cis aldo-hexose, suppresses development of saltinduced hypertension in Dahl rats. J. Hypertens. 23, 1887-1894. doi: 10.1097/ 01.hjh.0000182523.29193.e3

Lee, T. E., Shin, K. C., and Oh, D. K. (2018). Biotransformation of fructose to allose by a one-pot reaction using Flavonifractor plautii D-allulose 3-epimerase and Clostridium thermocellum ribose 5-phosphate isomerase. J. Microbiol. Biotechnol. 28, 418-424. doi: 10.4014/jmb.1709.09044

Levin, G. V. (2002). Tagatose, the new GRAS sweetener and health product. J. Med. Food 5, 23-36. doi: 10.1089/109662002753723197

Lim, Y. R., and Oh, D. K. (2011). Microbial metabolism and biotechnological production of D-allose. Appl. Microbiol. Biotechnol. 91, 229-235. doi: 10.1007/ s00253-011-3370-8
Lin, C. J., Tseng, W. C., and Fang, T. Y. (2011). Characterization of a thermophilic L-rhamnose isomerase from Caldicellulosiruptor saccharolyticus ATCC 43494. J. Agric. Food Chem. 59, 8702-8708. doi: 10.1021/jf201428b

Lin, C. J., Tseng, W. C., Lin, T. H., Liu, S. M., Tzou, W. S., and Fang, T. Y. (2010). Characterization of a thermophilic L-rhamnose isomerase from Thermoanaerobacterium saccharolyticum NTOU1. J. Agric. Food Chem. 58, 10431-10436. doi: 10.1021/jf102063q

Mitani, T., Hoshikawa, H., Mori, T., Hosokawa, T., Tsukamoto, I., Yamaguchi, F., et al. (2009). Growth inhibition of head and neck carcinomas by D-allose. Head Neck 31, 1049-1055. doi: 10.1002/hed.21070

Mooradian, A. D., Smith, M., and Tokuda, M. (2017). The role of artificial and natural sweeteners in reducing the consumption of table sugar: a narrative review. Clin. Nutr. Espen. 18, 1-8. doi: 10.1016/j.clnesp.2017.01.004

Morimoto, K., Park, C. S., Ozaki, M., Takeshita, K., Shimonishi, T., Granström, T. B., et al. (2006). Large scale production of D-allose from D-psicose using continuous bioreactor and separation system. Enzym. Microb. Technol. 38, 855-859. doi: 10.1016/j.enzmictec.2005.08.014

Mu, W., Zhang, W., Feng, Y., Jiang, B., and Zhou, L. (2012). Recent advances on applications and biotechnological production of D-psicose. Appl. Microbiol. Biotechnol. 94, 1461-1467. doi: 10.1007/s00253-012-4093-1

Murata, A., Sekiya, K., Watanabe, Y., Yamaguchi, F., Hatano, N., Izumori, K., et al. (2003). A novel inhibitory effect of D-allose on production of reactive oxygen species from neutrophils. J. Biosci. Bioeng. 96, 89-91. doi: 10.1016/ S1389-1723(03)90104-6

Park, C. S., Yeom, S. J., Kim, H. J., Lee, S. H., Lee, J. K., Kim, S. W., et al. (2007b). Characterization of ribose-5-phosphate isomerase of Clostridium thermocellum producing D-allose from D-psicose. Biotechnol. Lett. 29, 1387-1391. doi: 10. 1007/s10529-007-9393-7

Park, H. Y., Park, C. S., Kim, H. J., and Oh, D. K. (2007a). Substrate specificity of a galactose 6-phosphate isomerase from Lactococcus lactis that produces D-allose from D-psicose. J. Biotechnol. 132, 88-95. doi: 10.1016/j.jbiotec.2007.08.022

Poonperm, W., Takata, G., Okada, H., Morimoto, K., Granström, T. B., and Izumori, K. (2007). Cloning, sequencing, overexpression and characterization of L-rhamnose isomerase from Bacillus pallidus Y25 for rare sugar production. Appl. Microbiol. Biotechnol. 76, 1297-1307. doi: 10.1007/s00253-007-1109-3

Sanchez, S., and Smiley, K. L. (1975). Properties of D-xylose isomerase from Streptomyces albus. Appl. Microbiol. 29, 745-750. doi: 10.1128/aem.29.6.745750.1975

Seo, M. J., Choi, J. H., Kang, S. H., Shin, K. C., and Oh, D. K. (2018). Characterization of L-rhamnose isomerase from Clostridium stercorarium and its application to the production of D-allose from D-allulose (D-psicose). Biotechnol. Lett. 40, 325-334. doi: 10.1007/s10529-017-2468-1

Sui, L., Dong, Y., Watanabe, Y., Yamaguchi, F., Hatano, N., Izumori, K., et al. (2005a). Growth inhibitory effect of D-allose on human ovarian carcinoma cells in vitro. Anticancer Res. 25, 2639-2644.

Sui, L., Dong, Y., Watanabe, Y., Yamaguchi, F., Hatano, N., Izumori, K., et al. (2005b). The inhibitory effect and possible mechanisms of D-allose on cancer cell proliferation. Int. J. Oncol. 27, 907-912. doi: 10.3892/ijo.27.4.907

Xu, W., Zhang, W., Tian, Y., Zhang, T., Jiang, B., and Mu, W. (2017). Characterization of a novel thermostable L-rhamnose isomerase from Thermobacillus composti KWC4 and its application for production of D-allose. Process Biochem. 53, 153-161. doi: 10.1016/j.procbio.2016.11.025

Yoon, R. Y., Yeom, S. J., Park, C. S., and Oh, D. K. (2009). Substrate specificity of a glucose-6-phosphate isomerase from Pyrococcus furiosus for monosaccharides. Appl. Microbiol. Biotechnol. 83, 295-303. doi: 10.1007/s00253-009-1859-1

Conflict of Interest: B-JK was employed by the company DAESANG Corporation.

The remaining authors declare that the research was conducted in the absence of any commercial or financial relationships that could be construed as a potential conflict of interest.

Copyright $(2021$ Choi, Shin, Kim, Kim, Park, Yeom and Kim. This is an open-access article distributed under the terms of the Creative Commons Attribution License (CC BY). The use, distribution or reproduction in other forums is permitted, provided the original author(s) and the copyright owner(s) are credited and that the original publication in this journal is cited, in accordance with accepted academic practice. No use, distribution or reproduction is permitted which does not comply with these terms. 